\title{
Film Thickness and Friction of ZDDP Tribofilms
}

\author{
Joanna Dawczyk $^{1} \cdot$ Neal Morgan $^{2} \cdot$ Joe Russo $^{3} \cdot$ Hugh Spikes $^{1}$ (I)
}

Received: 22 December 2018 / Accepted: 5 February 2019 / Published online: 21 February 2019

(c) The Author(s) 2019

\begin{abstract}
Tribofilm formation by several zinc dialkyl- and diaryldithiophosphate (ZDDP) solutions in thin film rolling-sliding conditions has been investigated. A primary, a secondary alkyl and a mixed alkyl ZDDP show similar rates of film formation and generate films typically $150 \mathrm{~nm}$ thick. Another secondary ZDDP forms a tribofilm much faster and the film is partially lost after extended rubbing. An aryl ZDDP forms a tribofilm much more slowly. The films all have a pad-like structure, characterised by flat pad regions separated by deep valleys. Three different techniques have been used to analyse the thickness and morphology of the tribofilms: spacer layer imaging (SLIM), scanning white light interferometry (SWLI) of the gold-coated film and contact mode atomic force microscopy (AFM). The SLIM method measures considerably thicker films than the other two techniques, probably because of lack of full conformity of a glass disc loaded against the rough tribofilm. No evidence of a highly viscous layer on top of the solid tribofilm is seen. SWLI and contact mode AFM measure similar film thicknesses. The importance of coating the tribofilm with a reflective layer prior to using SWLI is confirmed. As noted in previous work, the formation of a ZDDP tribofilm is accompanied by a marked shift in the Stribeck friction curve towards higher entrainment speed. For a given ZDDP this shift is found to correlate with the measured tribofilm roughness, proving that it results from the influence of this roughness on fluid entrainment in the inlet.
\end{abstract}

Keywords ZDDP $\cdot$ Zinc dialkyldithiophosphate $\cdot$ Tribofilm $\cdot$ Antiwear $\cdot$ Film thickness $\cdot$ Friction $\cdot$ Roughness

\section{Background}

Zinc dialkyl- and diaryldithiophosphates (ZDDPs) were first introduced as lubricant anticorrosion, extreme pressure and oxidation inhibitor additives in the early 1940s, with their remarkable wear preventive properties being recognised a decade later in the 1950s [1]. Since then ZDDPs have been the antiwear additives of choice in almost all engine oils. In the 1990s, exhaust after-treatment systems were introduced in motor vehicles in order to reduce harmful emissions such as NOx, soot and unburnt hydrocarbons, and it was soon observed that sulphur and phosphorus compounds originating in part from ZDDP reduced the useful life of these systems [2]. This led to a progressive reduction in the levels of metallic elements, $\mathrm{P}$ and $\mathrm{S}$ allowed in engine oils

Hugh Spikes

h.spikes@imperial.ac.uk

Imperial College London, London, UK

2 Lubricants Discovery Hub, Shell Global Solutions, Manchester, UK

3 Shell Global Solutions, Houston, TX, USA and for some time the partial or complete replacement of ZDDP by alternative antiwear additives appeared imminent [3]. So far, however, no technology has been found as effective, versatile and cost-effective as ZDDP and the issue has instead been mitigated by the introduction in the most recent engine oil specifications of a phosphorus retention level [4]. This requires that at least $79 \%$ of the phosphorus content of the fresh oil still be present in the engine oil at the end of a prolonged engine test, implying that it has not found its way into the exhaust system. As well as enabling continued use of ZDDPs, this requirement has led to the increased choice of those ZDDPs having relatively low volatility [5].

The practical importance of ZDDPs, as well as the quest to find replacements for them, has meant that there has been a great deal of research to determine the nature of their tribofilms, the mechanisms by which they form these films and the ways that the films reduce wear. In the initial stages of rubbing when there is significant sliding metal/metal contact, iron sulphide is generated on rubbing steel surfaces [6] and this imparts extreme pressure protection [7]. In mild rubbing conditions, thick zinc phosphate/polyphosphatebased tribofilms then form on top of as well as mixed with 
this sulphide layer [6]. These films prevent direct mechanical and thus the adhesion between surface asperities and, since they contain only very small amounts of ferrous species, any wear that occurs after a ZDDP film is formed involves little, if any, ferrous material loss. It has also been suggested that the antiwear film behaves as a cushion, reducing the stress caused by substrate asperity peaks [8] and that ZDDP may react with ferrous wear particles embedded in the tribofilm reducing their abrasivity [9].

ZDDP tribofilms can form on rubbed surfaces even at temperatures as low as room temperature $[10,11]$ and the processes that control such film formation have been discussed for many years. Several driving agents have been suggested, including surface catalysis, triboemission, flash temperature and pressure, but it has recently been shown that ZDDP tribofilms form even during full film lubrication where there is no asperity contact so long as the shear stress is high enough. This suggests that applied stress coupled with temperature, is the main driver and that ZDDP film formation is thus a manifestation of mechanochemistry [12].

The precise sequence of reactions by which ZDDP molecules form zinc phosphate and polyphosphate films is still not well understood, although there have been many suggestions, mostly based on studies of the behaviour of ZDDPs in bulk solution rather than during rubbing. These include hydrolysis, intramolecular nucleophilic attack and $\mathrm{O} / \mathrm{S}$ exchange reactions [1]. It was found in the 1950s that the rate of ZDDP reaction was strongly dependent on the nature of the alkyl group, with ZDDPs formed from most secondary alcohols reacting faster than those formed from primary ones [13] and this has been confirmed in subsequent studies [14, 15]. Tribofilms obtained using ZDDPs based on aryl groups form very slowly and are less effective in reducing wear than those from alkyl ZDDPs [13, 16, 17]. This has led to the general supposition that the rate of ZDDP reaction to form an antiwear film is dependent on the strength of the $\mathrm{P}-\mathrm{O}$ or $\mathrm{C}-\mathrm{O}$ bond in the ZDDP molecule, which will be weakest for a secondary alkyl ZDDP and strongest for an aryl one [13], although the precise chemical reaction path has not been elucidated.

Until the late 1970s it was not clear whether ZDDP films were very thin, of the order of monolayers, or much thicker [18], the main problem being that it was not possible to gauge the extent to which removal of test specimens from the tribometer and subsequent surface analysis damaged any tribofilms present. In the late 1970s, in situ electrical contact resistance measurements suggested that quite thick films were formed but these could not be quantified because the electrical properties of the films were not known [19-21]. This was resolved in the late 1990s when Taylor et al. developed an optical interferometric method to monitor tribofilms without removing the rubbed test specimen from the test rig $[22,23]$. Another method that has been widely used in recent years to study ZDDP films is atomic force microscopy [24-27]. Both of these techniques show that ZDDPs form solid-like films on steel surfaces with a characteristic pad morphology consisting of flat islands typically $2-6 \mu \mathrm{m}$ in width, either round or elongated in the direction of sliding and separated by deep valleys containing little or no tribofilm. These pads grow during rubbing but then level out to a stable height of typically $100-150 \mathrm{~nm}$ from alkyl ZDDP solutions containing no other additives. In the absence of other additives such as aminic dispersants this stable thickness does not appear to result from the equilibrium between formation and removal of film but is inherent to the ZDDP film formation process. Some studies based on cryogenic analysis of ZDDP films and surface forces apparatus have suggested the presence of a viscous, solvent-removable layer, on top of the solid pad-structured tribofilm [28-30], but other work has found no evidence of such a layer [31].

During the late 1980s, the influence of engine oils on engine friction and thus fuel economy became an important issue and engine tests were introduced in lubricant specifications to quantify the impact of the lubricant on engine efficiency. From these it was found that some ZDDPs could be detrimental to fuel economy [32]. Initially this was assumed to originate from ZDDP tribofilms having high boundary friction and indeed it has been shown that boundary friction is strongly dependent on ZDDP alkyl structure [33]. However, by measuring the dependence of friction on entrainment speed and thus on EHD film thickness, it was also shown that ZDDPs produce a large increase in friction in mixed lubrication conditions $[34,35]$. The presence of a ZDDP tribofilm delays the formation of a hydrodynamic film to higher entrainment speeds, in effect shifting friction-speed curves towards higher speeds. Various reasons have been suggested for this, including the pad-valley ZDDP structure increasing the effective roughness of the surface [34] or liquid slip at the ZDDP tribofilm surface $[31,36]$.

In the current study we explore two main issues of ZDDP tribofilm formation. First the three main methods now used widely to measure and map ZDDP tribofilm thickness and roughness are compared. Then the measured frictionentrainment speed behaviour is correlated with surface roughness obtained from the AFM to confirm unambiguously for the first time that ZDDP film roughness is responsible for the observed increase in mixed friction.

\section{Test Materials}

A group II mineral oil containing a non-functionalised olefin copolymer (OCP) viscosity index improver was used as a base blend (BB). Such a blend, in combination with a detergent inhibitor pack, typically forms the basis for modern 
Table 1 Viscometric properties of base lubricant

\begin{tabular}{llll}
\hline Code & $\begin{array}{l}\text { Viscosity at } 40{ }^{\circ} \mathrm{C} \\
(\mathrm{m} \mathrm{Pa} \mathrm{s})\end{array}$ & $\begin{array}{l}\text { Viscosity at } \\
100{ }^{\circ} \mathrm{C}(\mathrm{m} \mathrm{Pa} \mathrm{s})\end{array}$ & Viscosity index \\
\hline Base blend & 43.34 & 7.531 & 167 \\
\hline
\end{tabular}

$5 \mathrm{~W} 30$ engine oils. Viscometric properties of BB were measured and are summarised in Table 1.

Five different ZDDPs were dissolved in the base blend, all at a concentration of $0.08 \% \mathrm{wt}$ P. The ZDDPs used are summarised in Table 2 . In this table $1^{\circ} / 1^{\circ}$ indicates two primary alkoxy- attached to a $\mathrm{P}$ atom, $2^{\circ} / 2^{\circ}$ two secondary alkoxyand $1^{\circ} / 2^{\circ}$ one primary and one secondary alkoxy-groups. All ZDDPs were predominantly neutral.

\section{Test Methods}

\subsection{MTM-SLIM}

ZDDP films were formed and their film thickness and frictional properties studied using a Mini Traction Machine with Spacer Layer Imaging (MTM-SLIM) [10, 35]. In the MTM a lubricated steel ball and disc are rubbed together in mixed sliding-rolling at controlled load and temperature while friction is monitored.

The Spacer Layer Imaging Method (SLIM) allows measurement of sub-micron thick tribofilms on rubbed steel balls in situ in the MTM. The principles of SLIM, which are based on optical interferometry, are shown in Fig. 1. During a measurement, rotation of the steel test ball is halted and it is uploaded against a coated glass mapper disc. White light is shone into the resulting contact where some is reflected by a semi-reflective coating on the underside of the glass while the remainder passes through a silica spacer layer and any antiwear film on the ball before being reflected back from the steel substrate. The two beams undergo optical interference depending on their optical path difference and thus on the antiwear film thickness. The result is an interference image

Table 2 ZDDP additives studied

\begin{tabular}{llllll}
\hline ZDDP type & Primary & Secondary & Secondary & Mixed & Aryl \\
\hline Code & Z1 & Z2 & Z3 & ZM & ZA \\
$\begin{array}{l}\text { P environment }(\%) \\
1^{\circ} / 1^{\circ}\end{array}$ & 85.5 & 33 & 2.5 & 42 & - \\
$2^{\circ} / 2^{\circ}$ & 9 & 67 & 89 & 43 & - \\
$1^{\circ} / 2^{\circ}$ & 5.5 & 0 & 8.5 & 15 & - \\
Aryl & 0 & 0 & 0 & 0 & 100 \\
Neutral $(\%)$ & & & & & \\
& 90 & 76 & 92 & 82 & 73 \\
\hline
\end{tabular}

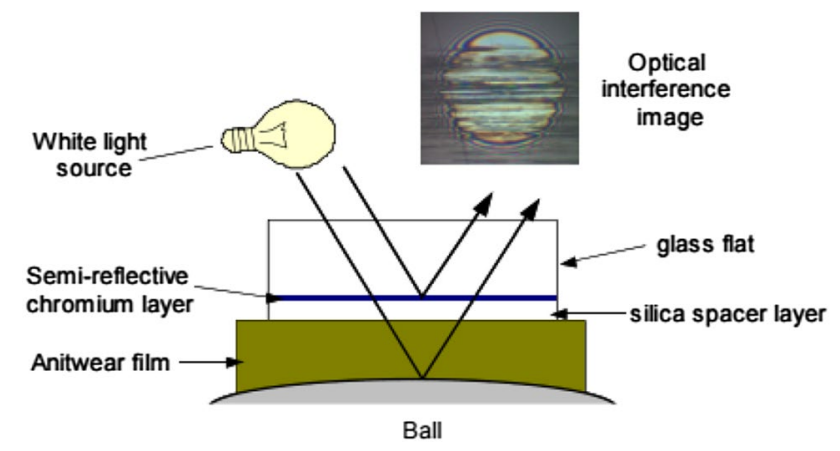

Fig. 1 The principles of spacer layer interferometry method

as shown in Fig. 1, which is captured as a RGB pixel map by a high resolution camera. A calibration chart of RGB colour versus optical path difference obtained using ultrathin film interferometry is then used to convert this RGB pixel map to a ZDDP tribofilm thickness map [37]. A refractive index of 1.6 was assumed for the ZDDP tribofilm. The advantage of SLIM is that tribofilm thickness is measured in situ without rinsing or cooling the MTM ball or removing it from the test rig.

In the current study AISI 52100 steel balls and discs were used. These were cleaned ultrasonically in toluene and then Analar isopropanol for $10 \mathrm{~min}$ prior to use. Tests lasted $3 \mathrm{~h}$ and involved slow speed rubbing to build ZDDP tribofilms, with periodic interference image capture using SLIM and Stribeck friction curve measurement to monitor tribofilm build up and friction.

The test sequence is shown schematically in Fig. 2. An initial SLIM interference image was taken before any rubbing commenced to determine the spacer layer thickness. Each rubbing step then involved rubbing the ball and disc at $50 \%$ SRR and a low entrainment speed of $50 \mathrm{~mm} / \mathrm{s}$ for a set time. This low entrainment speed produced a theoretical initial EHD film thickness of $5.5 \mathrm{~nm}$ and thus mixed lubrication conditions. After this slow speed rubbing the ball was uploaded against the glass disc and a SLIM interference image was captured. Finally a Stribeck friction curve was measured in which friction was measured over a range of entrainment speed at 50\% SRR to complete the rubbing step. Figure 5 shows typical sequences of SLIM images while Fig. 9 shows series of Stribeck curves for three of the ZDDP solutions.

Test conditions are summarised in Table 3.

\subsection{SWLI}

Scanning white light interference (SWLI) microscopy was first used successfully in tribology research by Tasan et al. to map wear on rubbed surfaces with high resolution [38]. Benedet et al. investigated the use of SWLI as a 
Fig. 2 MTM-SLIM test sequence
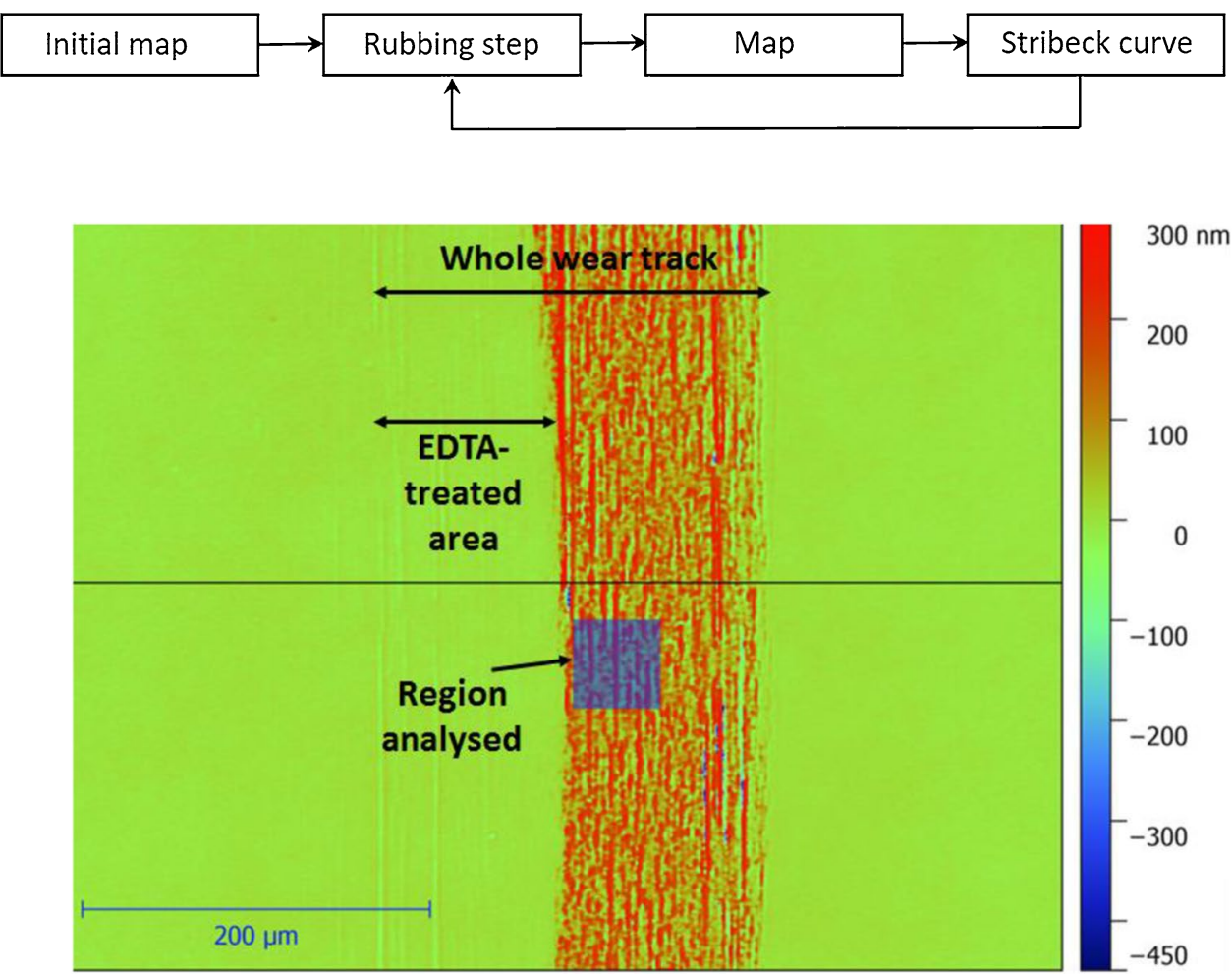

Fig. 3 SWLI image of goldcoated ZDDP tribofilm. The left hand half of the film has been removed using EDTA solution. Blue square region shows area from which film thickness and roughness are analysed. (Color figure online) measurement technique for ZDDP antiwear film thickness and noted that internal reflections within the transparent tribofilm could lead to misleading measurements [39]. They showed that ZDDP tribofilms could, however, be made reflective using a thin layer of gold. This approach, coupled with the use of ethylenediamine tetraacetic acid (EDTA) solution to locally remove ZDDP film, enabled the thickness of film to be mapped using SWLI.

In the current study, after an MTM test, the ball and disc specimens were rinsed with heptane. The specimens were then dried and a drop of $0.05 \mathrm{M}$ EDTA solution was placed on part of the wear track on both ball and disc and wiped off after $60 \mathrm{~s}$. The aim was to check if any significant amount of wear was present underneath the antiwear film, and also to provide a reference plane on each side of the analysed area of interest [17]. Then the rubbed area of interest was coated with ca $25 \mathrm{~nm}$ of gold both to avoid spurious internal reflection within any antiwear film and to provide constant reflection properties inside and outside the rubbed track. An SWLI microscope (Wyko NT9100) was then employed in vertical scanning interferometry (VSI) mode to capture a topography image across the whole width of wear track as shown in Fig. 3. Height and roughness values of the film were obtained from the $50 \times 50 \mu^{2}$ region close to the centre of the track and marked as a blue square in Fig. 3.

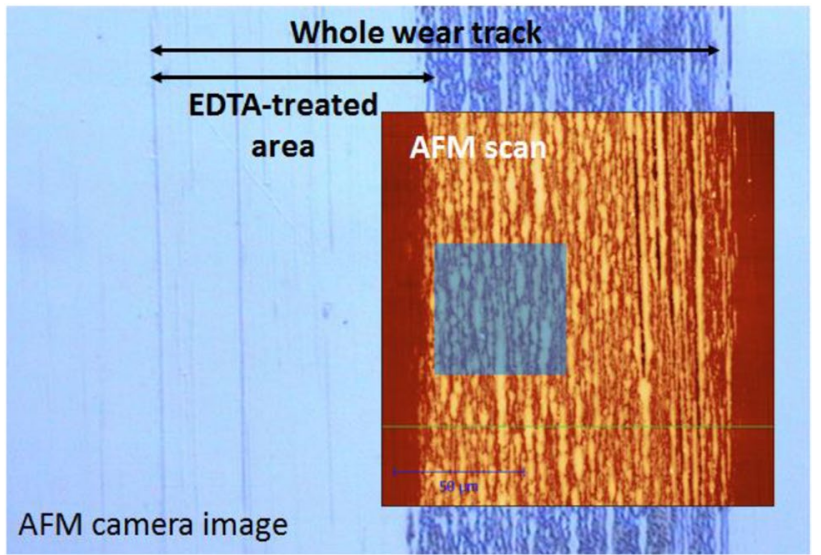

Fig. 4 AFM image of part of tribofilm. The left hand side of the tribofilm has been removed using EDTA solution to provide a reference plane

\subsection{AFM}

Atomic force microscopy (AFM) is arguably one of the most powerful techniques to study the topography [17, 24-27] and also, as demonstrated by Gosvami et al., to monitor the formation of antiwear films [40].

MTM discs which had been previously cleaned for the purpose of SWLI measurement were used for AFM measurement, studying a region of the rubbed track that had not been coated with gold. For this study, a 
Table 3 Conditions of MTM test

\begin{tabular}{lll}
\hline & Stribeck curve & Rubbing step \\
\hline Duration (min) & - & $3,3,4,5,15,30,60,60$ \\
Slide to roll ratio (SRR) (\%) & 50 & 50 \\
Ball load (N) & 31 & 31 \\
Entrainment speed (mm/s) & Decreasing from 3500 to 7 & 50 \\
\hline
\end{tabular}

Fig. 5 Series of SLIM pictures obtained during $3 \mathrm{~h}$ test

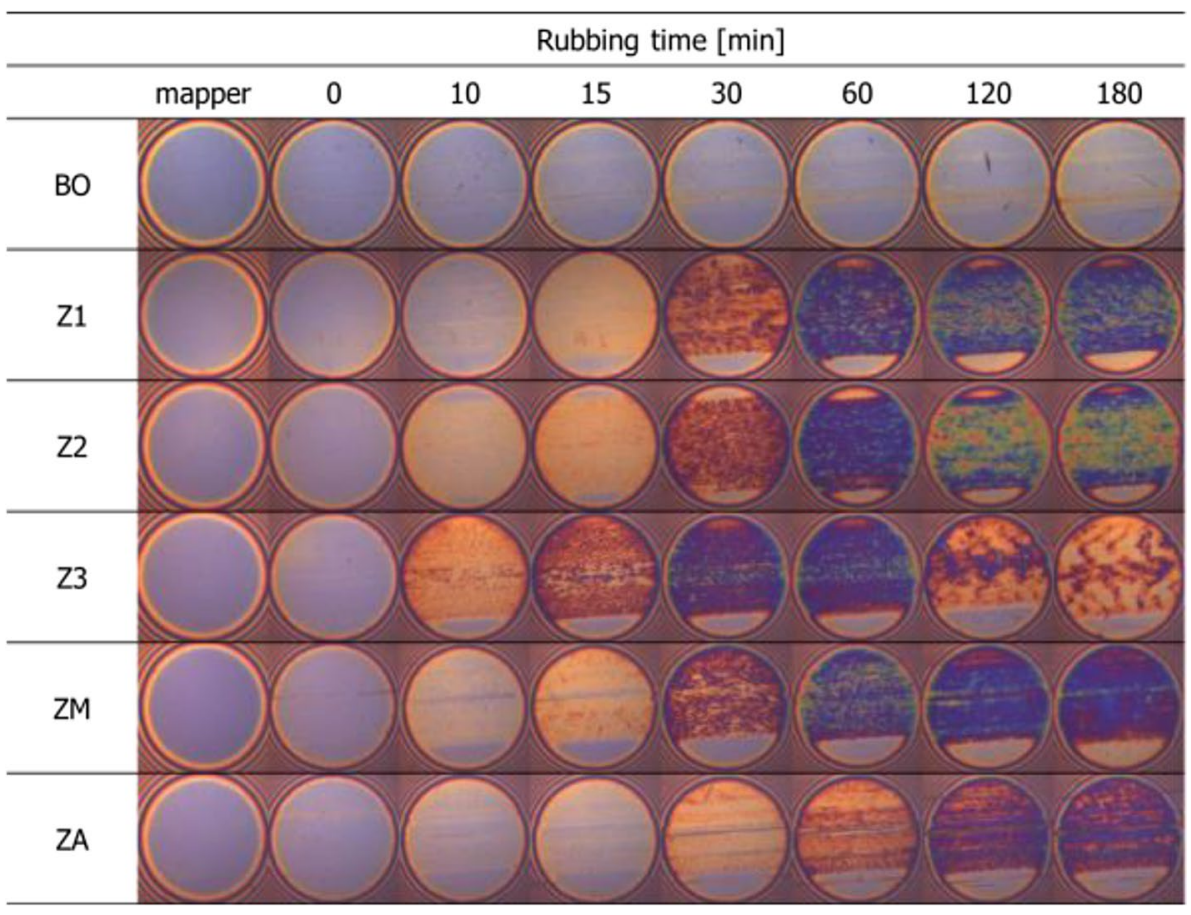

confocal AFM-Raman alpha300 RA produced by WiTec was employed. As for SWLI study, half of the wear track width was treated with EDTA solution to provide a reference plane close to the centre of the track as shown in Fig. 4. AFM topography images were then taken from a $150 \times 150 \mathrm{~mm} 2$ region but, like SWLI, film thickness and roughness values were determined only from a $50 \times 50 \mu \mathrm{m}^{2}$ area, as shown in Fig. 4.

\subsection{EHD Film Thickness}

To help understand the effect of ZDDP tribofilms on lambda ratio and thus friction, the elastohydrodynamic (EHD) filmforming properties of the test fluids in the absence of such films was required. EHD film thickness was measured using a PCS ultrathin film measurement system [41]. A $19.5 \mathrm{~mm}$ diameter steel ball on coated glass disc contact in nominally pure rolling was studied over a range of entrainment speeds at a load of $20 \mathrm{~N}$ and a temperature of $100{ }^{\circ} \mathrm{C}$. In practice, the concentration levels of ZDDP used (ca $1 \%$ wt.) had negligible effect on fluid viscosity and film thickness so the data used in this paper are those of the base fluid blend.

\section{Results}

\subsection{MTM - SLIM Film Formation}

Figure 5 shows sequences of optical interference images obtained from the track on the ball after rubbing for predefined periods of time. The pale blue images result from optical interference due to the spacer layer alone, while 


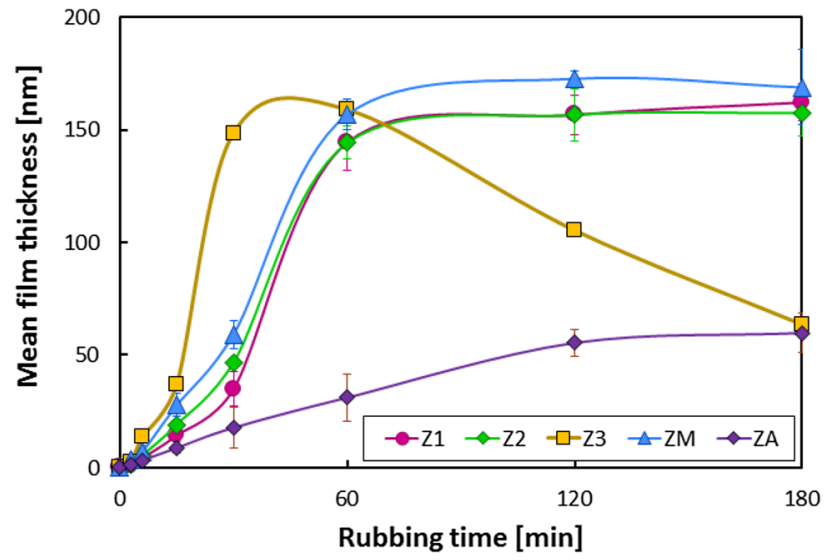

Fig. 6 Development of ZDDP antiwear film during $3 \mathrm{~h}$ tests, from SLIM images

these changes to orange and eventually brown and dark blue as a tribofilm develops to increase the optical path difference. Before the ZDDP solutions were studied, the base blend was tested and neither significant tribofilm formation nor severe wear were observed. From Fig. 5 it is evident that all ZDDPs form a tribofilm that can be detected by interferometry after 10 min rubbing.

Mean antiwear film thickness in the central region of the contact area versus rubbing time calculated from the interference colours via calibration is summarised in Fig. 6. The results shown are the means from three repeat tests and for all except $\mathrm{Z} 3$ the standard deviations are shown. The growth of the film can be divided into two stages. During the first phase the film develops rapidly, while in the second phase the thickness of antiwear film usually stabilises, typically after $1 \mathrm{~h}$ of rubbing. There is some evidence of an initial "induction period" having slow film growth rate before the onset of rapid film formation [42]. The film formation rates and final thicknesses of $\mathrm{Z1}, \mathrm{Z} 2$ and ZM are quite similar although the differences are statistically significant since repeatability was very good. The final film thickness ranges from $160 \mathrm{~nm}$ (Z2) to $170 \mathrm{~nm}(\mathrm{Z} 1$ and $\mathrm{ZM})$. ZA forms a film slowly and this stabilises at a thickness of ca $60 \mathrm{~nm}$. Z3 forms a film very rapidly but this film appeared to become unstable after about $1 \mathrm{~h}$ of rubbing and is partially lost in the later stages of a test. This loss occurred in all three tests but occurred at different rubbing times between 60 and 120 min. Films formed by Z2, Z3 and ZA at the end of $3 \mathrm{~h}$ tests are compared as optical images in Fig. 7. With Z2 the film is rough but evenly distributed in the track; for Z3 it is very patchy with areas where almost the complete film are lost but others when the original thickness remains. ZA forms a film that is quite even along the rubbing direction but very variable transverse to this. The films formed by $\mathrm{Z} 1$ and $\mathrm{ZM}$ were evenly distributed like those from $\mathrm{Z} 2$.

\subsection{MTM Friction}

Figure 8 shows three series of Stribeck curves obtained after various rubbing times for Z1, Z2 and Z3. Each curve shown is a mean from three repeat tests and standard deviations are shown on the graphs, although in many cases these are obscured by the mean data points. For Z1 and $\mathrm{Z} 2$ there is a clear trend of the curves shifting to the right during rubbing, so that the transition from boundary through mixed to full film EHD lubrication occurs at higher entrainment speed as the tribofilm develops. For Z3, Fig. 8 shows that initially the friction-speed curves shift to the right, just as for $\mathrm{Z} 1$ and $\mathrm{Z} 2$. This happens very rapidly, correlating with the fact that tribofilm formation occurs very quickly. However after $60 \mathrm{~min}$ the friction curves move back towards the original shape, which corresponds to the observed partial loss of the tribofilm seen with SLIM.

Figure 9 compares Stribeck curves of all the ZDDP solutions after $180 \mathrm{~min}$ rubbing. $\mathrm{Z1}, \mathrm{ZA}$ and $\mathrm{ZM}$ are quite similar in shape and have almost identical friction at low entrainment speed. Z2 looks different from the others but this is because it has a significantly lower boundary
$\mathrm{Z1}$

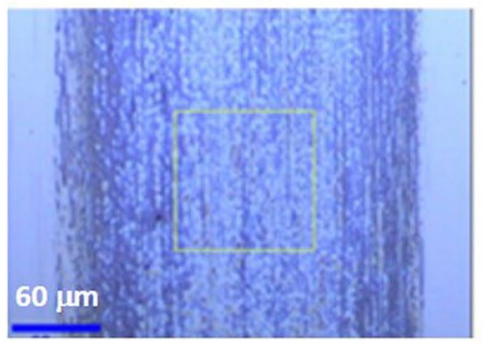

Z3

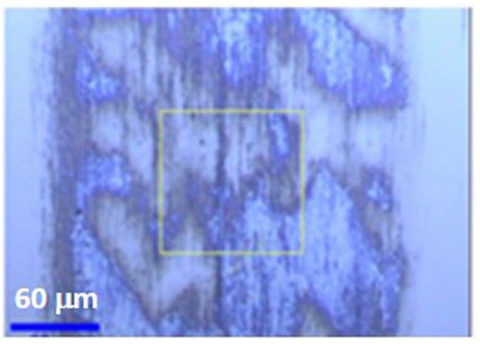

ZA

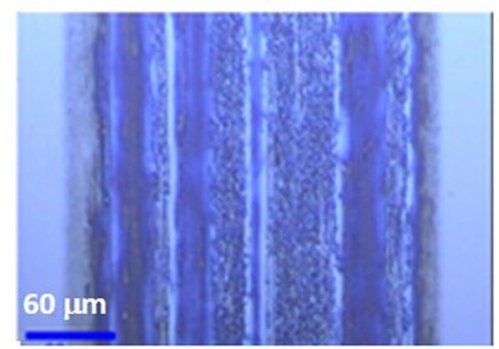

Fig. 7 Microscope images of a Z2, b Z3, c ZA 

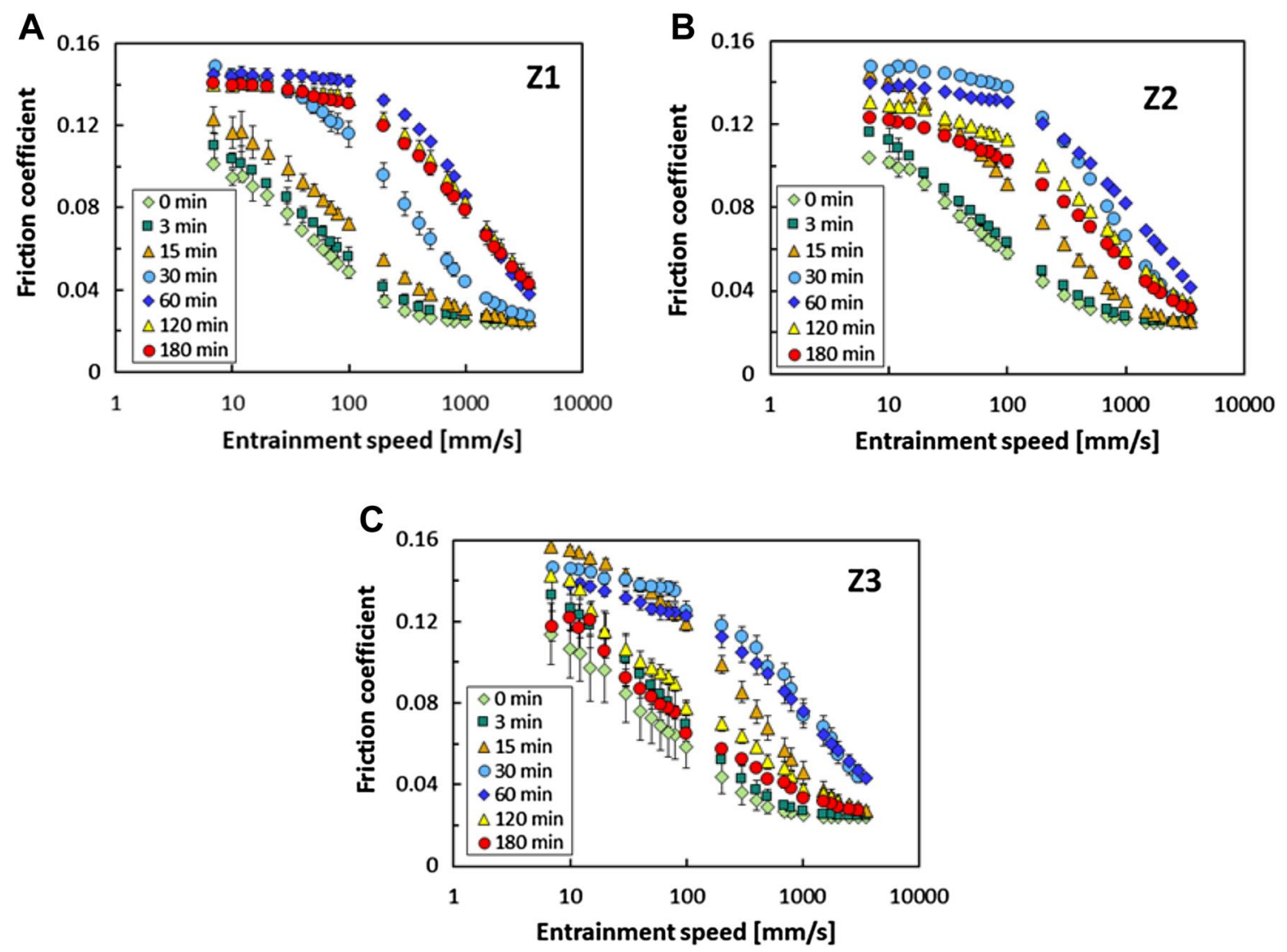

Fig. 8 Friction coefficient versus entrainment speed curves obtained during rolling-sliding tests for a Z1, b Z2 and $\mathbf{c}$ Z3. SRR=50\%, load $=31 \mathrm{~N}$, temperature $=100^{\circ} \mathrm{C}$

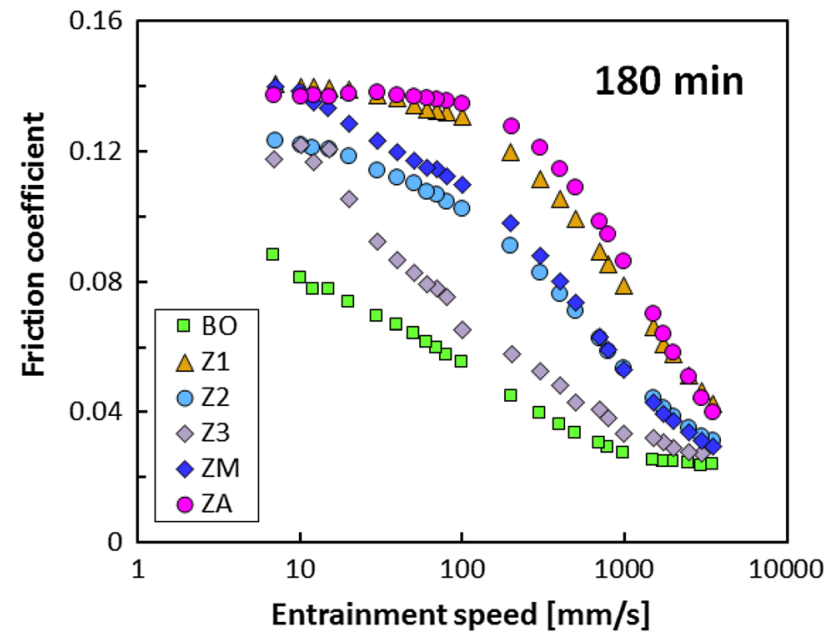

Fig. 9 Stribeck curves obtained after $3 \mathrm{~h}$ of rubbing friction, as evident at low speed. If this curve were scaled by the difference in boundary friction $(0.118$ for $\mathrm{Z} 2$ and ca 0.14 for the others) it would be very similar. Previous work has shown that the boundary friction of alkyl ZDDPs is quite strongly dependent on the alkyl groups present, with linear chains giving lower friction than branched ones $[33,43]$.

\section{Discussion: Film Thickness}

\subsection{SWLI Measurements}

Figure 10a shows an SWLI image of a gold-coated part of the rubbed track on an MTM disc obtained after a test with Z2. Cross-sections of the height across the rubbed track on a rubbed ball and disc after a 3 h rubbing test with 

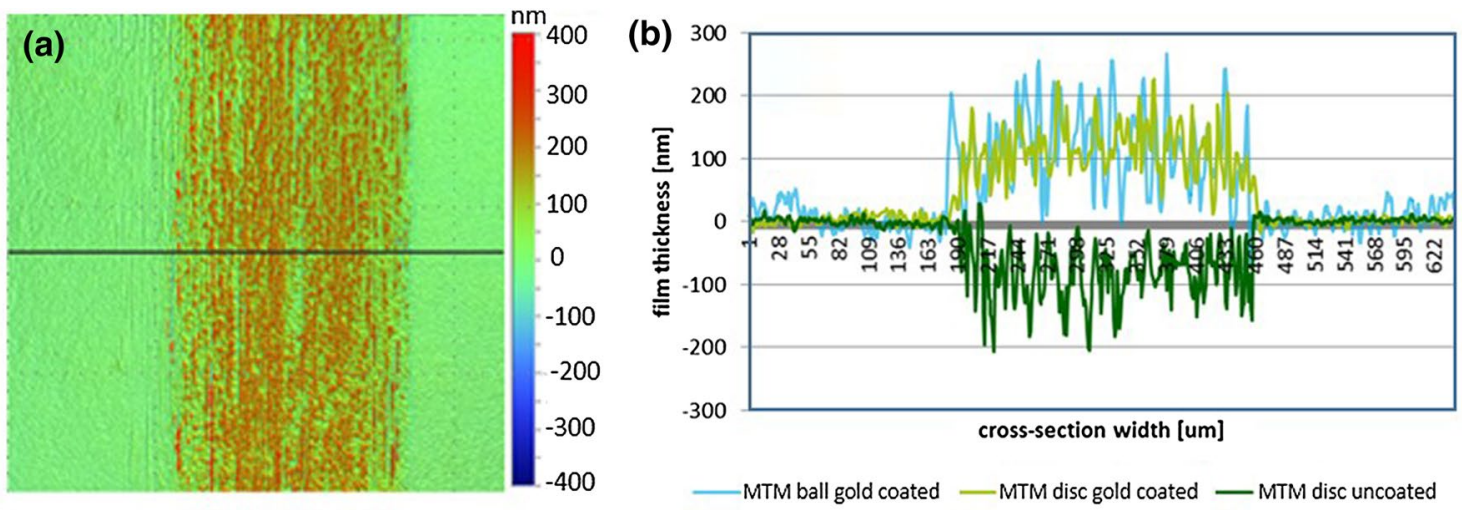

Fig. 10 a SWLI image of antiwear film on MTM disc. b Profiles of antiwear films on coated and uncoated MTM specimens

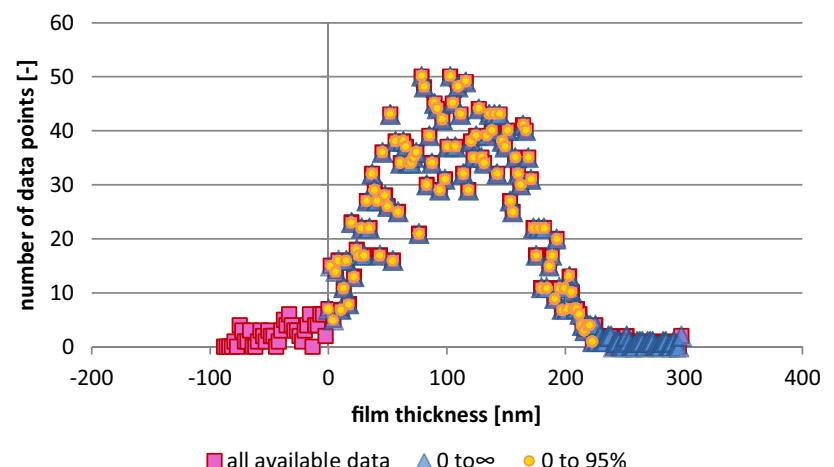

Fig. 11 Distribution of $\mathrm{Z1}$ tribofilm thickness for Z1solution after 180 min test

$\mathrm{Z} 2$ are shown in Fig. 11b. One is from a non gold-coated part of the disc and suggests a negative height, i.e. wear. However the other two profiles are from the disc and ball after coating with a thin gold film. It can now be seen that there is a similar film on both surfaces, of thickness approximately $110 \mathrm{~nm}$, with some regions reaching over $200 \mathrm{~nm}$ thickness. As shown by Benedet et al. [39], it is evident that the rubbed track has to be covered with a thin, reflective coating to avoid spurious SWLI measurements. From Fig. $10 \mathrm{~b}$ it can also be seen that the antiwear film is thinner close to the edge of unrubbed surface. Initially the thickness of antiwear film was measured on both ball and disc. The aim of it was to check if the film was similar on both rubbed surfaces. In fact the thicknesses were very similar and further study was thus made only on the disc, which was preferred for comparison with the AFM technique since large areas could not be scanned reliably on the ball using AFM because its curvature.

Mean film thickness from analysed disc specimens was calculated based on averaging four $50 \times 50 \mathrm{~mm}^{2}$ areas around the wear track close to centre, as shown in Fig. 3. From each area, each pixel was analysed and results

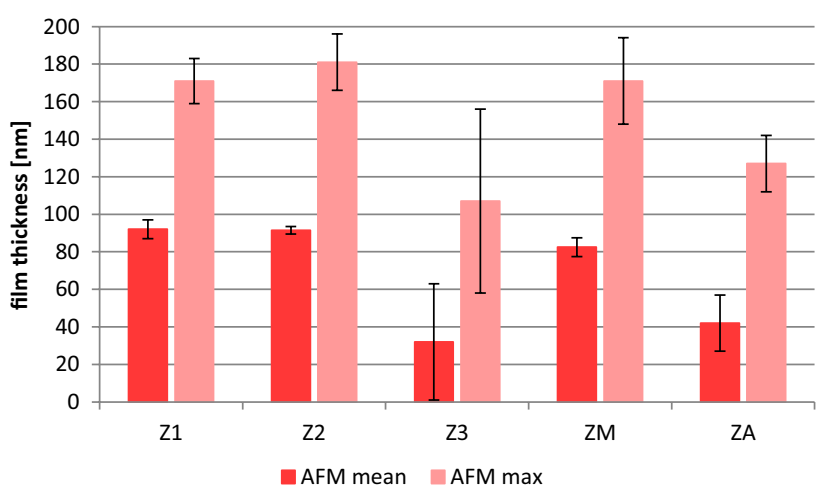

Fig. 12 Film thickness of ZDDPs using AFM

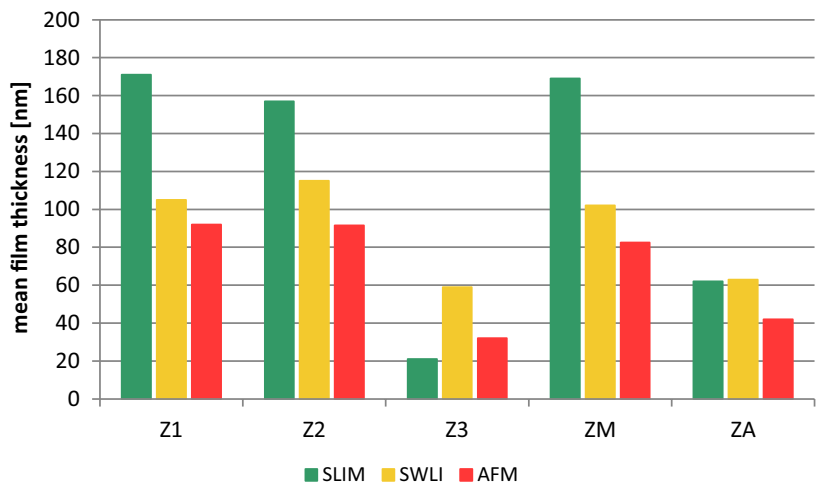

Fig. 13 Comparison of mean tribofilm thickness results of ZDDPs using three measurement methods

extracted as a histogram as shown in Fig. 11. Most of the film has thickness $30-200 \mathrm{~nm}$. The few negative results in Fig. 11 probably represent individual pixels where the incorrect optical order was chosen by the SWLI software, combined with an imperfect zeroing of the baseline, rather than wear. The points below $0 \mathrm{~nm}$ were therefore excluded 
when calculating mean film thickness. It is also likely that an incorrect order may have led to the few very high values seen in Fig. 11. Values above $230 \mathrm{~nm}$ were therefore also excluded from calculation of mean film thickness although in practice since there are so few such points, they had only slight effect on the calculated mean. However, uncertainty concerning these points meant that it was difficult to estimate the maximum film thickness using SWLI.

\subsection{AFM Measurements}

AFM was used to scan several central regions around the disc and mean and maximum film thickness values were calculated from $50 \times 50 \mu^{2}$ areas, as shown in Fig. 4. The values from different regions were then averaged, as shown in Fig. 12. For Z1 and Z2 the standard deviation was low (ca

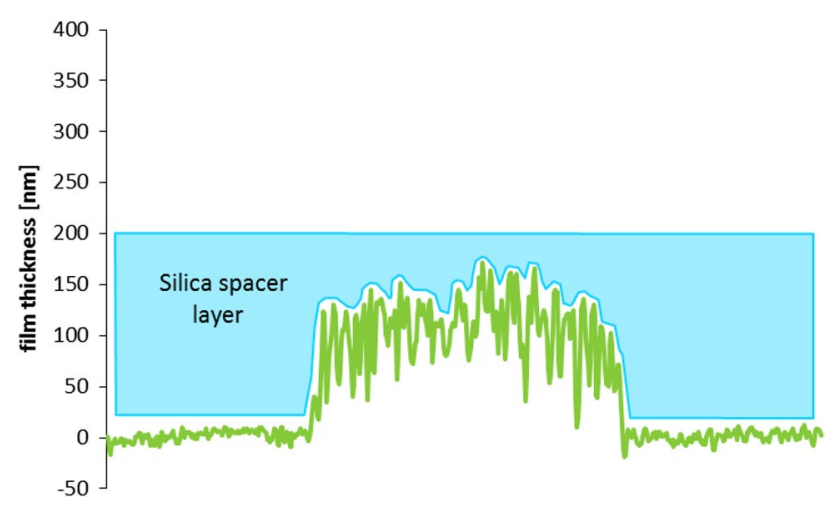

Fig. 14 Schematic showing limited conformation of silica spacer layer to ZDDP tribofilm. (It should be noted that the width of the ZDDP film is ca $250 \mu \mathrm{m}$ while its height is ca $150 \mathrm{~nm}$, so the actual slopes of the film roughness are much less than shown in the figure)
$6 \%$ indicating that the antiwear films were evenly distributed along the wear track. Z3 formed thinner antiwear films with large variation in thickness between analysed regions ranging from 20 to $100 \mathrm{~nm}$.

\subsection{Comparison of Methods}

Figure 13 compares the mean film thicknesses measured using the three experimental techniques for all ZDDPs.

For the ZDDPs that formed stable, thick antiwear films, $\mathrm{Z} 1, \mathrm{Z} 2$ and $\mathrm{ZM}$, it is evident that SLIM measures considerably thicker mean film thickness than AFM and SWLI. As discussed by Topolovec [17], this is believed originate from the fact that SLIM involves a coated glass disc being loaded against the tribofilm and measures the separation between glass disc and steel ball substrate rather than the actual tribofilm thickness. Because the ZDDP tribofilm consists of pads separated by deep, narrow valleys it is unlikely that the glass disc can fully conform to the tribofilm surface within the valleys, as illustrated schematically in Fig. 14. The non-conformed valley regions will thus augment the separation due to the tribofilm itself, making the latter's thickness appear greater than it actually is and quite close to the maximum film thickness value. This observation is supported by the fact that the mean values obtained using SLIM and maximum film thickness of averaged areas using AFM were similar, as can be seen by comparing Figs. 12 and 13. Topolovec et al. also found that maximum film thickness of ZDDP films was similar when measured using SLIM and AFM but did not calculate the mean values [17].

In the case of $\mathrm{Z} 3$ the three methods give quite different film thickness measurements. This probably originates from the very patchy, uneven nature of the film at the end
Fig. 15 Comparison of film thickness distribution plots for Z2 tribofilm after $180 \mathrm{~min}$ test measured using AFM and SWLI. Inset is AFM topography map

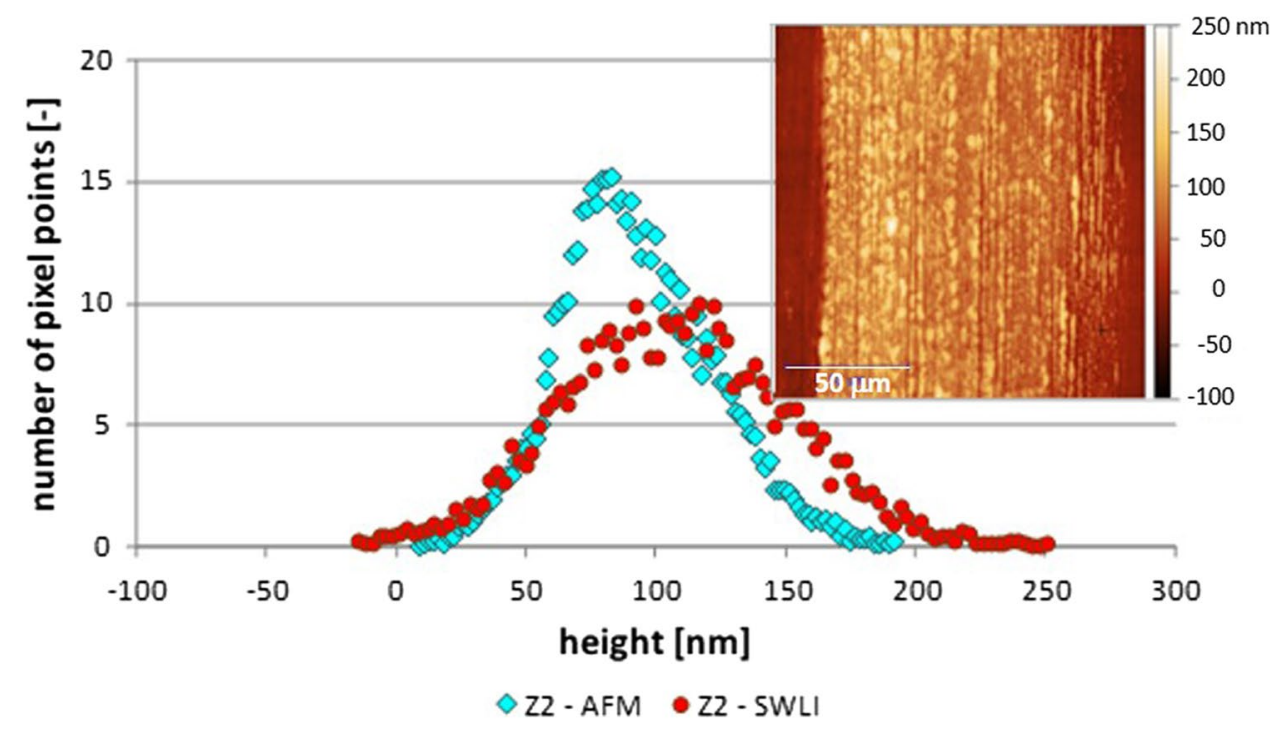


Fig. 16 SLIM images of ZDDP tribofilm covered with thin, viscous oil film showing entrapment formed with highly viscous oil film

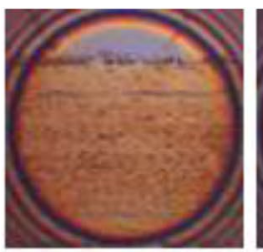

Original ZDDP film

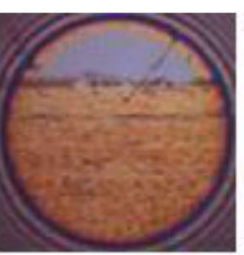

Oil film $22 \mathrm{cP}$

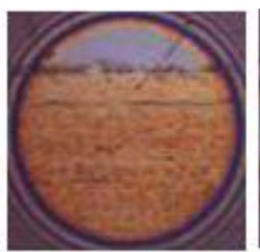

Oil film $153 \mathrm{cP}$

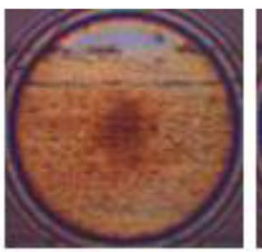

Oil film $235 \mathrm{mPas}$

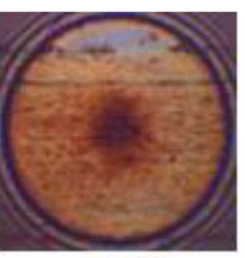

Oil film $358 \mathrm{mPas}$ of the tests, which is evident from Fig. 7. This means that the measured film thickness was strongly dependent on the regions chosen for analysis. With SWLI and AFM several measurements were taken around the track and averaged but these showed considerable variations, while for SLIM only one measurement was made at the end of each test. For ZA, SLIM and SWLI give similar mean film thickness while for AFM the film is considerably thinner. Again this probably arises from large variations in film thickness across the rubbed track.

In general, SWLI gives a film thickness around $20 \mathrm{~nm}$ greater than AFM. This may be an optical effect in which the beam reflected from the coated surface of the antiwear film rebounds from the edges of antiwear film pads resulting in the seemingly longer path of the reflected beam. It is unlikely to represent the thickness of the gold film applied in SWLI since this also coats the reference surface outside the rubbed track. Figure 15 compares film thickness histograms of a Z2 tribofilm obtained using AFM and SWLI and shows that the SWLI distribution is quite different from that measured using AFM and that perhaps some of the valleys are filled with gold.

Based on the above it is clear that the three methods of measuring ZDDP films have different strengths and weaknesses. The very great advantage of SLIM is that it enables tribofilm formation to be monitored throughout a test, providing a series of thickness values as the test progresses. This enables film growth rate (and also removal rate) to be studied very easily and conveniently: to obtain similar information using AFM or SWLI a series of tests of different duration must be carried out, as described in Sect. 6.1. Unfortunately, as this study confirms, the actual mean film thickness values (and also the roughness values) obtained using SLIM are quite inaccurate - the trends seen are correct but the actual values of mean film thickness are overestimates, though they do approximate to maximum thickness values. SWLI can only be carried out at the end of a test since it requires a gold coating to be applied. It can be easily applied to both ball and disc surfaces and is experimentally straightforward but does appear to produce some artefacts where analysis predicts a negative and possible a falsely high film thickness. Gold coating also skews the height distribution, possibly by filling some of the valleys. AFM is also generally applied at the end of a test though it could in principle be used in fully immersed mode during tests as was done by Gosvami et al. [40]. It is quite difficult to apply to an MTM ball due to the latter's curvature, but reasonably straightforward on the MTM disc. It can only analyse a relatively small area that may not span the whole track width, necessitating removal of part of the film to determine film thickness in the track centre. Based on this this study it is believed that measurements using AFM are the most reliable.

\subsection{Comparison of ZDDPs}

The film-forming behaviour found in this study using different types of ZDDP is broadly similar to previous studies, with aryl ZDDP forming thinner films more slowly than alkyl ones [13, 16, 17]. Previous work has generally found that secondary alkyl ZDDPs form films faster than primary ones. In the current study one secondary ZDDP, Z2, formed a film at about the same rate as the primary and mixed one while another secondary one, Z3, formed a film extremely rapidly. This is probably because, as shown in Table 2, Z3 consists almost entirely of secondary ZDDP molecules while Z2, although described by the supplier as secondary, actually consists of a 2:1 blend of secondary and primary ZDDPs. Thus the true concentration of secondary ZDDP is only $0.53 \mathrm{wt} \% \mathrm{P}$. Z2 also contains a higher proportion of basic ZDDP molecules. Topolovec also noted differences in film formation between secondary ZDDPs but focussed on the final film thickness formed [17]. The current study suggests that the rate of film formation is more sensitive to alkyl ZDDP structure than the maximum tribofilm thickness formed.

\subsection{Viscous Surface Layer}

As discussed in the Sect. 1 section, some researchers have identified the presence of a viscous surface layer, possibly consisting of alkyl phosphate precipitates, on top of the generallyaccepted solid-like ZDDP tribofilm [28-30], although other work has shown no such film [31]. It has been suggested that this film is removed during solvent washing and therefore is not normally seen in ex-situ studies [30]. In SLIM the rubbed ball surface is neither rinsed nor cooled so any viscous ZDDP film forms should be present when the ball is loaded against 
the coated glass disc. It is well known that the normal approach of a ball on a flat coated with oil can result in the rate of formation of a local entrapment or "dimple" as the rate of increase of the pressure and thus viscosity rise within the centre of the contact exceeds the rate at which fluid can flow radially from the contact centre [44-46]. This phenomenon depends of the rate of normal approach and the viscosity and pressure viscosity coefficient of the fluid. If a highly viscous film were present on top the ZDDP tribofilm, this should form such an entrapment. However no entrapment was seen in the current work using SLIM when the ball was uploaded against the coated glass disc, as indicated in the images in Fig. 5. To test what viscosity of surface film would produce an entrapment on a rough ZDDP film, a ball with a rinsed ZDDP tribofilm was coated with thin films of base oils of various viscosities and uploaded against the glass disc using the standard SLIM load and approach rate. It was found that an entrapment was formed only for films of viscosity greater than $150 \mathrm{mPas}$, as shown in Fig. 16. This implies that if a viscous film is present on top of the solid ZDDP tribofilm it must have viscosity less than ca $200 \mathrm{mPas}$. This is much less than the value of $5.10^{4}$ to $3.10^{5}$ Pas estimated by Bec et al. [30].

\section{Discussion: Friction}

As in previous studies [34, 35], a very striking evolution of friction was seen during ZDDP tribofilm formation (Figs. 8, 9), with friction at intermediate speed increasing far more than friction at very low or very high speed. The most widely suggested mechanism for this is that the ZDDP film behaves as a solid tribofilm to increase surface roughness and thus inhibit fluid entrainment. This has, however, not been definitively proven and to test it in the current study the measured friction versus entrainment speed curves were converted to friction versus effective lambda ratio curves as follows.

\subsection{Estimation of Lambda Ratios}

First AFM measurements were made of the roughness of the MTM tribofilm surfaces during tests. Since AFM can only be applied at the end of a test a series of tests of different duration were carried out. Results are shown in Table 4 for Z1 and Z2. It is important to note that the same area of $50 \times 50 \mathrm{~mm}^{2}$ was used for all determinations since it is well known that roughness increases as the size of the area analysed increases, due to the incorporation of longer and longer wavelength features [47].
The EHD film-forming properties of the fluids studied were then determined by measuring the BB film thickness using optical interferometry at the test temperature of $100{ }^{\circ} \mathrm{C}$, as shown in Fig. 17. This shows classical EHD behaviour, with film thickness dependent on entrainment speed according to a best fit of;

$h_{\mathrm{c}}=0.574 U^{0.633}$

where $h_{\mathrm{c}}$ is the central film thickness (in $\mathrm{nm}$ ) and $U$ the entrainment speed (in $\mathrm{mm} / \mathrm{s}$ ).

Equation 1 applies to a glass flat (elastic modulus $70 \mathrm{Ga}$ ) on steel ball (elastic modulus $210 \mathrm{GPa}$ ) contact in pure rolling at a load of $20 \mathrm{~N}$. In the MTM contact used in the current study, both ball and flat were steel and the applied load was $31 \mathrm{~N}$. The radius of the ball was the same in both film thickness and MTM experiments. To allow for the difference in elastic modulus and load, Eq. 1 was adjusted using the dependence of EHD film thickness on load and elastic modulus expressing in the Chittenden equation [48]. In practice, EHD film thickness is only weakly dependent on load and elastic modulus so this gave a very slight adjustment relationship to;

$h_{\mathrm{c}}=0.544 U^{0.633}$

In practice EHD film thicknesses were measured in pure rolling while MTM tests were carried out at 50\% slide/roll ratio (SRR). However it is well known that EHD film thickness varies only very slightly with SRR up to 50\% [49].

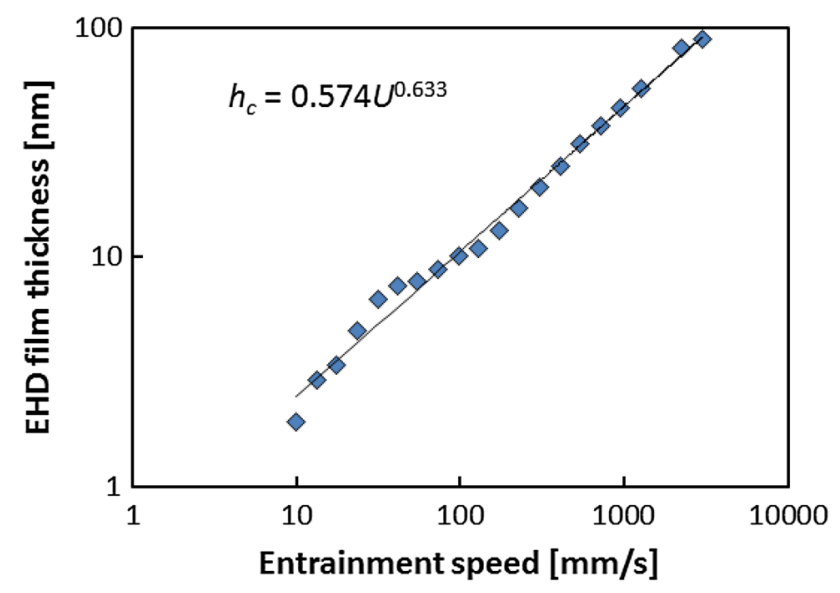

Fig. 17 Variation of EHD central film thickness with entrainment speed using ultrathin film interferometry (base blend at $100{ }^{\circ} \mathrm{C}$ )
Table 4 Root mean square roughness $(\mathrm{Rq})$ of rubbed disc track surface at end of test

\begin{tabular}{lllllll}
\hline Test duration & $0 \mathrm{~min}$ & $15 \mathrm{~min}$ & $30 \mathrm{~min}$ & $60 \mathrm{~min}$. & $120 \mathrm{~min}$ & $180 \mathrm{~min}$ \\
\hline $\mathrm{Z} 1, \mathrm{Rq}$ of disc track $(\mathrm{nm})$ & 4 & 9 & 22.5 & 39.5 & 39.5 & 38.5 \\
$\mathrm{Z} 2, \mathrm{Rq}$ of disc track $(\mathrm{nm})$ & 4 & 14.5 & 32 & 49.5 & 41 & 27.5 \\
\hline
\end{tabular}




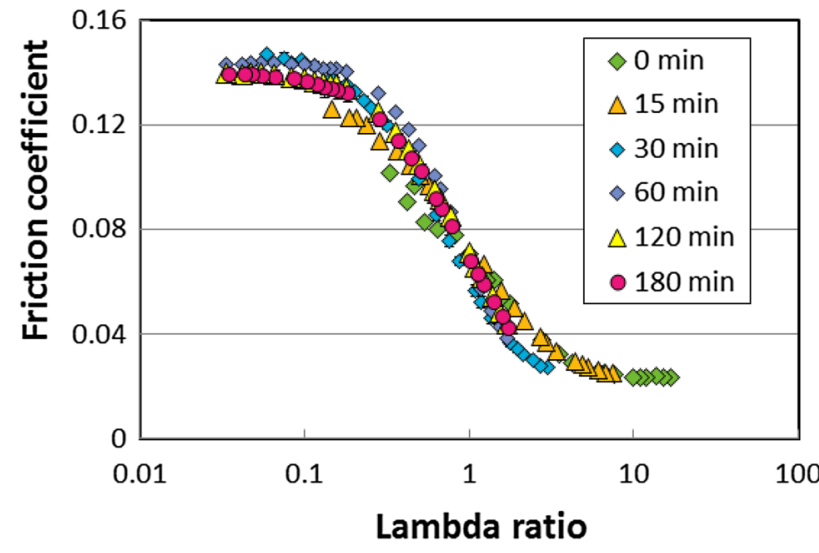

Fig. 18 Variation of measured friction coefficient with calculated lambda ratio for $\mathrm{Z} 1$ solution after various rubbing times

From surface roughness and EHD film thickness, the lambda ratio (defined as ratio of central film thickness to composite surface roughness) can be calculated, where composite surface roughness, $R_{\mathrm{qc}}$ is given by

$R_{\mathrm{qc}}=\sqrt{R_{q 1}^{2}+R_{q 2}^{2}}$

where $R q 1$ and $R q 2$ are the roughnesses of the disc and ball respectively. In this study the roughness of the ball was taken to be the same as that measured from the disc so that;

$R_{\mathrm{qc}}=\sqrt{2} R_{q 1}$

The lambda ratio is thus given by;

$\lambda=\frac{0.365 U^{0.696}}{\sqrt{2} R_{q 1}}$

Equation 5 can be used to convert plots of friction coefficient versus entrainment speed as shown in Figs. 8 and 9 to plots of friction coefficient versus lambda ratio. This is shown for Z1 in Fig. 18. It is evident that all the plots now coincide quite closely, indicating that a single Stribeck curve describes the transition from boundary to mixed lubrication at all stages of $\mathrm{Z} 1$ tribofilm growth. This strongly suggests that the shift in friction curve seen with ZDDP originates from the influence of the tribofilm on roughness in the contact inlet.

\subsection{Fraction of Boundary Lubrication}

In principle the collapse onto a single master Stribeck curve seen in Fig. 16 should be the same for all ZDDP tribofilms except that the bounding values of boundary friction coefficient at very low lambda ratio may differ between ZDDPs. This can be taken into account if we consider friction in mixed lubrication to arise from the sum of boundary and EHD components so that;

$F=F_{\mathrm{B}}+F_{\text {EHD }}$

where $F_{\mathrm{B}}$ is the load supported by asperity contacts operating in the boundary lubrication regime and $F_{\mathrm{EHD}}$ is the load supported by EHD fluid film pressure.

Equation 6 can be written as

$\mu W=\mu_{\mathrm{b}} W_{\mathrm{B}}+\mu_{\mathrm{EHD}} W_{\mathrm{EHD}}$

where $\mu_{\mathrm{EHD}}$ and $\mu_{\mathrm{B}}$ are now the friction coefficients in boundary and full film EHD conditions, $\mu$ is the overall friction coefficient and $W$ the applied load.

If $X$ is the fraction of applied load supported by boundary film then;

$\mu=\mu_{\mathrm{B}} X+\mu_{\mathrm{EHD}}(1-X)$

A similar equation was described by Beltzer and Jahanmir [50].

Equation 8 can be rearranged in terms of the fraction of load supported by boundary lubrication

$X=\frac{\mu-\mu_{E H D}}{\mu_{B}-\mu_{E H D}}$

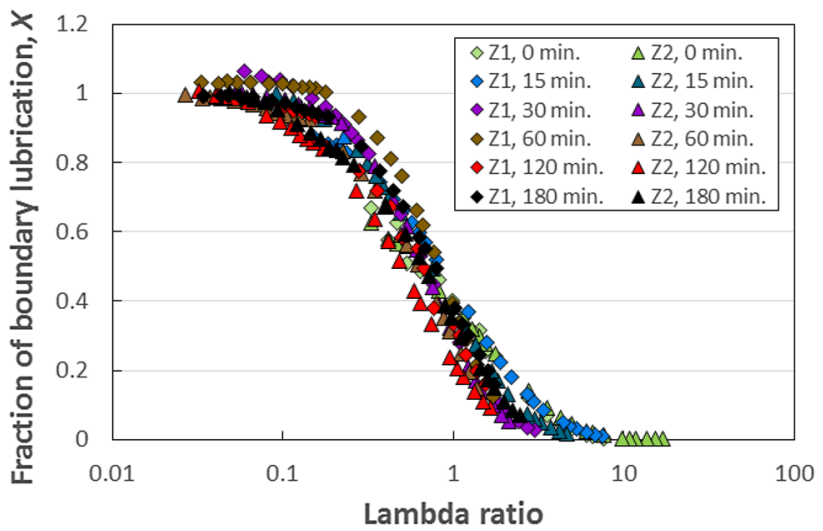

Fig. 19 Variation of fraction of boundary lubrication with lambda ratio for $\mathrm{Z} 1$ and $\mathrm{Z} 2$ solution, showing collapse onto a general master curve
Table 5 Boundary friction coefficient $\mu_{\mathrm{B}}$ used in determining $X$

\begin{tabular}{lllllll}
\hline Test duration & $0 \mathrm{~min}$ & $15 \mathrm{~min}$ & $30 \mathrm{~min}$ & $60 \mathrm{~min}$ & $120 \mathrm{~min}$ & $180 \mathrm{~min}$ \\
\hline $\mathrm{Z} 1 \mu_{B}$ & 0.147 & 0.147 & 0.147 & 0.144 & 0.140 & 0.140 \\
$\mathrm{Z} 2 \mu_{B}$ & 0.153 & 0.153 & 0.148 & 0.14 & 0.13 & 0.123 \\
\hline
\end{tabular}


so that any plot of the variation of friction coefficient, $\mu$, versus entrainment speed can be converted to one of $X$ versus entrainment speed (or lambda ratio) so long as $\mu_{\mathrm{EHD}}$ and $\mu_{\mathrm{B}}$ are known.

The value of $\mu_{\mathrm{EHD}}$ is the asymptote value of friction coefficient measured at high speed for the smooth surface (rubbing time $=0$ ) and represents the EHD friction coefficient at $100{ }^{\circ} \mathrm{C}, 50 \% \mathrm{SRR}$ and $31 \mathrm{~N}$ load for the base blend. This can be seen in Fig. 8 to have the value 0.024 . The value of $\mu_{\mathrm{B}}$ is the asymptote of the friction coefficient after rubbing at low speeds from Fig. 8. For Z1 this varies only slightly with rubbing time but for $\mathrm{Z} 2$ is reduced quite markedly after prolonged running. Values from Fig. 8 used in the current analysis are shown in Table 5.

Figure 19 shows plots of this fraction $X$ versus lambda ratio for $\mathrm{Z} 1$ and $\mathrm{Z} 2$. It is evident that both ZDDPs collapse onto a single master curve at all rubbing times when plotted in this way. This is further proof that the rise in mixed friction with ZDDPs results from the effect of ZDDP tribofilm roughness on fluid entrainment. It can be seen from Fig. 19 that under the load conditions used, the contact operates in full boundary lubrication to a lambda ratio of ca 0.1 and reaches full EHD lubrication at a lambda value of ca 5. This is in reasonable agreement with both experimental and modelling predictions of the effect of roughness on friction in point contact $[51,52]$.

\section{Conclusions}

The tribofilm formation of several ZDDP solutions in thin film, rolling-sliding conditions has been investigated. All the ZDDPs studied form tribofilms on steel surfaces during rubbing. A primary, a secondary and a mixed alkyl ZDDP all show similar rates of film formation to generate films that reach 100-200 nm thickness. A different secondary alkyl ZDDP shows much faster film formation but the film becomes unstable after about $1 \mathrm{~h}$ of rubbing and patches of it are lost from the surfaces. An aryl ZDDP forms tribofilm much more slowly. This film reaches only about $50 \mathrm{~nm}$ thickness and has a band-like structure along the rubbing direction, with negligible tribofilm present in some regions.

The tribofilms formed were quantified using three different techniques, spacer layer imaging (SLIM), scanning white light interferometry (SWLI) of the gold-coated film and contact mode AFM. The SLIM method measures considerably thicker mean film thickness than the other two techniques, probably because of lack of full conformity of a glass disc loaded against the rough tribofilm. However it remains the only method able to monitor film thickness throughout an MTM test. SWLI and AFM measure similar film thicknesses, with those determined by AFM being slightly thinner than using SWLI. The importance of coating the tribofilm with a reflective layer prior to using SWLI has been confirmed.

As noted in previous work, the formation of a ZDDP tribofilm is accompanied by a marked shift in the Stribeck-type friction curve towards higher entrainment speed. By measuring the roughness of the ZDDP tribofilm using AFM at the end of a series of tests of different duration, it is possible to transform these friction curves to ones showing the variation of friction coefficient with surface roughness. This has the effect of collapsing the curves after different rubbing times and thus provides strong evidence that the increase in mixed friction seen with ZDDPs is due to the formation of a rough, solid tribofilm surface that reduces fluid entrainment. Further transformation of friction coefficient to the fraction of boundary lubrication within the contact produces a single master curve showing experimentally how the transition from boundary to fluid film lubrication depends on the lambda ratio. This provides a way to predict the influence of ZDDPs on friction at all conditions based on the roughness of their tribofilms and their boundary friction coefficients.

Acknowledgements The authors wish to acknowledge the support of Shell via the Shell Imperial College University Technology Centre for Fuels and Lubricants.

Open Access This article is distributed under the terms of the Creative Commons Attribution 4.0 International License (http://creativeco mmons.org/licenses/by/4.0/), which permits unrestricted use, distribution, and reproduction in any medium, provided you give appropriate credit to the original author(s) and the source, provide a link to the Creative Commons license, and indicate if changes were made.

\section{References}

1. Spikes, H.A.: The history and mechanisms of ZDDP. Tribol. Lett. 17, 469-489 (2004)

2. Bodek, K.M., Wong, V.V.: The effects of sulfated ash, phosphorus and sulfur on diesel aftertreatment systems: a review SAE Technical Paper No. (2007-01-1922) (2007)

3. Spikes, H.A.: Low and zero-sulphated ash, phosphorus and sulphur anti-wear additives for engine oils. Lubr. Sci. 20, 1893-1901 (2008)

4. International Lubricants Standardization and Approval Committee (ILSAC): ILSAC GF-5 Standard for Passenger Car Engine Oils, Sect. 3.a. Publ. ILSAC 2009

5. Wang, L., Wang, L., Li, G., Xu, X.: The effect of ZDDP type on phosphorus volatility: engine oil performance on Sequence IIIG and field tests. SAE Technical Paper, No. 2013-01-2570 (2013)

6. Shimizu, Y., Spikes, H.A.: The tribofilm formation of ZDDP under pure sliding, reciprocating conditions. Tribol. Lett. 64, 46 (2016)

7. Sieber, I., Meyer, K., Kloss, H.: Characterization of boundary layers formed by different metal dithiophosphates in a four-ball machine. Wear. 85, 43-56 (1983)

8. Hutchings, I.M. Tribology-Friction \& Wear of Engineering Materials. Elsevier Limited, Oxford (1992)

9. Martin, J.J.: Antiwear mechanisms of zinc dithiophosphate: a chemical hardness approach. Tribol. Lett. 6, 1-8 (1999) 
10. Fujita, H., Spikes, H.A.: Formation of zinc dithiophosphate antiwear films. Proc. Inst. Mech. Eng. Part J. 218, 265-277 (2004)

11. Fujita, H., Glovnea, R.P., Spikes, H.A.: Study of zinc dialkydithiophosphate antiwear film formation and removal processes, part I: experimental. Tribol. Trans. 48, 558-566 (2005)

12. Zhang, J., Spikes, H.A.: On the mechanism of ZDDP antiwear film formation. Tribol. Lett. 63, 1-15 (2016)

13. Asseff, P.A.: A surface effect associated with the use of oils containing zinc dialkyl dithiophosphate. ASLE Trans. 2, 78-90 (1959) (Discussion to Bennett, P.A., 1959)

14. Jones, R.B., Coy, R.C.: The chemistry of the thermal degradation of zinc dialkyldithiophosphate additives. ASLE Trans. 24, 91-97 (1981)

15. Coy, R.C., Jones, R.B.: The thermal degradation and EP performance of zinc dialkyldithiophosphate additives in white oil. ASLE Trans 24, 77-90 (1981)

16. Yamaguchi, E.S., Ryason, P.R., Labrador, E.Q., Hansen, T.P.: Comparison of the relative wear performance of neutral and basic ZnDTP salts. Tribol. Trans. 39, 220-224 (1996)

17. Topolovec-Miklozic, K., Forbus, T.R., Spikes, H.A.: Film thickness and roughness of ZDDP antiwear films. Tribol. Lett. 26, 161-171 (2007)

18. Gunsel, S., Spikes, H.A., Aderin, M.: In-situ measurement of ZDDP films in concentrated contacts. Tribol. Trans. 36, 276-282 (1993)

19. Georges, J.M., Martin, J.M., Mathia, T., Kapsa, P., Meille, G., Montes, H.: Mechanism of boundary lubrication with zinc dithiophosphate. Wear. 53, 9-34 (1979)

20. Tonck, A.J.M.P.H.J.M., Martin, J.M., Kapsa, P., Georges, J.M.: Boundary lubrication with anti-wear additives: study of interface film formation by electrical contact resistance. Tribol. Intern. 12, 209-213 (1979)

21. Yamaguchi, E.S., Ryason, P.R., Yeh, S.W., Hansen, T.P.: Boundary film formation by ZnDTPs and detergents using ECR. Tribol. Trans. 41, 262-272 (1998)

22. Taylor, L.A., Glovnea, R., Ribeaud, M., Spikes, H.A.: The nature and properties of antiwear additive films. In: Proceeding of the ITC Conference, Nagasaki, Oct. 2000, vol II, pp. 1257-1262, JST, Tokyo (2001)

23. Taylor, L.J.: The film-forming and wear-reducing properties of antiwear additives. PhD thesis, University of London (2001)

24. Pidduck, A.J., Smith, G.C.: Scanning probe microscopy of automotive anti-wear films. Wear. 212, 254-264 (1997)

25. Aktary, M., McDermott, M.T., McAlpine, G.A.: Morphology and nanomechanical properties of ZDDP antiwear films as a function of tribological contact time. Tribol. Lett. 12, 155-162 (2002)

26. Aktary, M., McDermott, M.T., Torkelson, J.: Morphological evolution of films formed from thermooxidative decomposition of ZDDP. Wear. 247, 172-179 (2001)

27. Mikložič, K.T., Spikes, H.A.: Application of atomic force microscopy to the study of lubricant additive films. ASME Trans. J. Tribol. 127, 405-415 (2005)

28. Bell, J.C., Delargy, K.M., Seeney, A.M.: The removal of substrate material through thick zinc dithiophosphate anti-wear films. In: Dowson D. et al. (ed.) Proceeding of the 18th Leeds-Lyon Symposium on Tribology, Wear particles: from the cradle to the grave. Lyon, Sept. 1991, pp. 387-396. Elsevier (1992)

29. Bell, J.C., Delargy, K.M.: The composition and structure of model zinc dialkyldithiophosphate anti-wear films. In: Proceeding of the 6th International Congress on Tribology, Eurotrib'93, vol. 2, pp. 328-332, Budapest (1993)

30. Bec, S., Tonck, A., Georges, J.M., Coy, R.C., Bell, J.C., Roper, G.W.: Relationship between mechanical properties and structures of zinc dithiophosphate anti-wear films. Proc. R. Soc. Lond. A455, 4181-4203 (1999)
31. Taylor, L.J., Spikes, H.A.: Friction-enhancing properties of ZDDP antiwear additive: part II: influence of ZDDP reaction films on EHD lubrication. Tribol. Trans. 46, 310-314 (2003)

32. Kennedy, S., Moore, L.D.: Additive effects on lubricant fuel economy. SAE Trans. 96, 681-691 (1987)

33. Aoki, S., Suzuki, A., Masuko, M.: Comparison of sliding speed dependency of friction between steel surfaces lubricated with several ZnDTPs with different hydrocarbon moieties. Proc. Inst. Mech. Eng. Part J. 220, 343-351 (2006)

34. Tripaldi, G., Vettor, A., Spikes, H.A.: Friction behavior of ZDDP films in the mixed, boundary/EHD regime. SAE Technical Paper No. 962036 (1996)

35. Taylor, L.J., Spikes, H.A.: Friction-enhancing properties of ZDDP antiwear additive: part I: friction and morphology of ZDDP reaction film. Tribol. Trans. 46, 303-309 (2003)

36. Berro, H., Fillot, N., Vergne, P.: Molecular dynamics simulation of surface energy and ZDDP effects on friction in nano-scale lubricated contacts. Tribol. Intern. 43, 1811-1822 (2010)

37. Choo, J.W., Olver, A.V., Spikes, H.A.: Influence of surface roughness features on mixed film lubrication. Lubr. Sci. 15, 219-232 (2003)

38. Taşan, Y.C., De Rooij, M.B., Schipper, D.J.: Measurement of wear on asperity level using image-processing techniques. Wear. 258, 83-91 (2005)

39. Benedet, J., Green, J.H., Lamb, G.D., Spikes, H.A.: Spurious mild wear measurement using white light interference microscopy in the presence of antiwear films. Tribol. Trans. 52, 841-846 (2009)

40. Gosvami, N.N., Bares, J.A., Mangolini, F., Konicek, A.R., Yablon, D.G., Carpick, R.W.: Mechanisms of antiwear tribofilm growth revealed in situ by single-asperity sliding contacts. Science. 348, 102-106 (2015)

41. Johnston, G.J., Wayte, R., Spikes, H.A.: The measurement and study of very thin lubricant films in concentrated contacts. Tribol. Trans. 34, 187-194 (1991)

42. Fujita, H., Spikes, H.A.: The study of zinc dialkyldithiophosphate anti-wear film formation and removal process. Part II: Kinetic model. Tribol. Trans. 48, 567-575 (2005)

43. Hoshino, K., Yagashita, K., Tagawa, K., Spikes, H.A.: Tribological properties of sulphur-free antiwear additives zinc dialkylphosphates (ZDPs). SAE Technical Paper No. 2011-01-2132, JSAE 20119056 (2011)

44. Dowson, D., Jones, D.A.: Lubricant entrapment between approaching elastic solids. Nature. 214(5091), 947 (1967)

45. Paul, G.R., Cameron, A.: An absolute high-pressure microviscometer based on refractive index. Proc. R. Soc. Lond. A331, 171-184 (1972)

46. Kaneta, M., Ozaki, S., Nishikawa, H., Guo, F.: Effects of impact loads on point contact elastohydrodynamic lubrication films. Proc. Inst. Mech. Eng. J. 221, 271-278 (2007)

47. Sayles, R.S., Thomas, T.R.: Surface topography as a nonstationary random process. Nature. 271, 431-434 (1978)

48. Chittenden, R.J., Dowson, D., Dunn, J.F., Taylor, C.M.: A theoretical analysis of the isothermal elastohydrodynamic lubrication of concentrated contacts. I. Direction of lubricant entrainment coincident with the major axis of the Hertzian contact ellipse. Proc. R. Soc. Lond. A397, 245-269 (1985)

49. Smeeth, M., Spikes, H.A.: The influence of slide/roll ratio on the film thickness in EHD contact operating in the mixed lubrication regime. In: D. Dowson et al. (ed.) Proceeding of the 22nd Leeds/Lyon Symposium on Tribology, The Third Body Concept: Interpretation of Tribological Phenomena, Lyon, Sept. 1995, pp. 695-703, Elsevier (1996)

50. Jahanmir, S., Beltzer, M.: An adsorption model for friction in boundary lubrication. ASLE Trans. 29, 423-430 (1986) 
51. Guegan, J., Kadiric, A., Gabelli, A., Spikes, H.A.: Relationship between friction and film thickness in EHD point contact in the presence of longitudinal roughnesses. Tribol. Lett. 64, 33 (2016)

52. Zhu, D., Wang, J., Wang, Q.J.: On the Stribeck curves for lubricated counterformal contacts of rough surfaces. Trans. ASME, J. Tribol. 137, 021501 (2015)
Publisher's Note Springer Nature remains neutral with regard to jurisdictional claims in published maps and institutional affiliations. 